\title{
REPORT OF THE COMMITTEE ON METEORITES
}

Several monographs and collections of papers were published in Meteoritics during 1967 to 1969 (Chirvinskij, 1967; Vdovykin, 1967; Wood, 1968; Cikulin, 1969; Anders et al., 1967; Stanjukovič, 1968). Extensive work on meteorites is continuing in the Meteorite Committee of the Academy of Sciences of U.S.S.R. Fesenkov and Krinov continued publishing the journal Meteoritika, where most of the papers of scientists of the U.S.S.R. are published. Hoffleit continued publishing Meteoritics of the Meteorite Society. Javnel' continued editing a bibliography on meteorites. A bibliography on the isotopic and chemical composition of meteorites was published by Kielbasinski and Wanat. The UNESCO working group on meteorites under the chairmanship of Orcel edited the Directory of Meteorite Collections and Meteorite Research in 1968.

The Meteorite Committee of the Academy of Sciences of the U.S.S.R. organized its 13th meteorite conference in 1968. The Meteorite Society had its 30th to 32nd annual meetings during 1967 to 1969. The International Atomic Agency in cooperation with UNESCO and five other international scientific unions and organizations including the IAU represented by Millman, prepared a Symposium on Meteorite Research in Vienna, Austria, 7-13 August, 1968, initiated by the UNESCO Working Group on Meteorites. More than 70 papers were presented at this Symposium, showing the interests of various sciences in meteorites. The Symposium volume appeared very soon after the sessions were closed in the series Astrophysics and Space Science Library, published by D. Reidel Publishing Company, Dordrecht, Holland, under the title Meteorite Research edited by P. M. Millman (1969, 940 pages).

The information on new meteorite falls and finds continued in the Meteoritical Bulletin edited by Krinov. In 1968, another source of data on newly fallen meteorites started to be available in an information circular published by the Center for Short-Lived Phenomena at the Smithsonian Astrophysical Observatory, Cambridge, U.S.A. (Citron). During the period from January 1, 1967 to November 1, 1969, 12 meteorite falls were reported, among which two carbonaceous chondrites, Pueblito de Allende in Mexico and Murchison in Australia, which fell during 1969. Short lived isotopes were detected in 5 of these meteorites. The ratio of $\mathrm{Ar}^{37}$ to $\mathrm{Ar}^{39}$ in the Alandroal iron meteorite was found to be low by Fireman, which could be due to variations of cosmic rays in space.

Many papers dealt with the isotopic composition of primordial gases in meteorites and their different compounds. The maximum concentration of primordial gases ( $\mathrm{He}, \mathrm{Ne}, \mathrm{Ar}$ ) was found in fine-grain matrix material by Megrue using a laser microprobe and a mass spectrometer. This could be explained by injection of material from the solar wind.

Radiogenic gases and isotopes were measured by many people. The measurements of the time after the nucleosynthesis until gases were maintained resulted in about 100-200 million years for chondrites, using the ratio $\mathrm{I}^{129} / \mathrm{Xe}^{129}$ (Gerling, Manuel, Alexander). Another method for the determination of this interval is based on the $\mathrm{Pu}^{244} / \mathrm{Xe}^{136}$ ratio and gives more or less identical results according to several authors (Kuorda, Rao). The $\mathrm{Xe}^{136}$ content is higher in chondrites than in achondrites (Reynolds), which could be connected with the spontaneous fission of a super-heavy element with $Z=112-119$ (Dakowski, Anders, Heymann). The $\mathrm{Rb}^{87} / \mathrm{Sr}^{87}$ ages were measured for several meteorites. The results on the silicate phase of iron meteorites are in the interval from 4.7 to $3.8 \times 10^{9} \mathrm{yr}$ which is in agreement with the $\mathrm{K}^{40} / \mathrm{Ar}^{40}$ ages (Wasserburg, Burnett).

Extensive rare gas isotope, mineralogical and chemical work is being performed at the MaxPlanck-Institut in Heidelberg. A large number of stony meteorites has been studied: Primordial rare gases were detected in several chondrites, e.g., Phum Sambo, Barratta and Hedjas (Müller, Zähringer). The isotopic composition of lithium which is significant for the early irradiation history of meteorites, was determined by Krankowsky and Müller in a large number of meteorites. Radioactive isotopes were detected. The light and dark phases of the amphoterite chondrites showed unusual high alkali contents giving a precise Rb-Sr-age of $4.70 \times 10^{9} \mathrm{yr}$. Carbon and rare gases were found to be correlated to the mineralogical classification by Otting and Zähringer. In 45 meteorites, cosmogenic rare gases were analysed by Nord and Zähringer. The K-Ar age of iron 
meteorites was found to be about $5 \times 10^{9} \mathrm{yr}$ for a few specimens using improved techniques.

Extensive work on meteorites is being performed at the Max-Planck-Institut für Chemie in Mainz. It was shown by Begemann et al. that considerable fractions of $\mathrm{Ar}^{39}$ and $\mathrm{P}^{32}$ activities in stone meteorites are produced by neutrons in the $10 \mathrm{MeV}$ region. The deduced neutron fluxes vary considerably, depending more probably on the orbital elements than on the size of the meteoroids (Begmann and Wänke). Other parameters strongly related to meteoroid orbits were also found: (a) Loss of tritium from iron meteorites and the metal phase of chondrites (Hintenberger et al., Schultz). (b) Loss of $\mathrm{He}^{3}$ from pyroxene and feldspar (Hintenberger). Both effects are caused by solar heating at the perihelion. From $\mathrm{Be}^{10}, \mathrm{Cl}^{36}$ and other cosmic-ray products, the terrestrial ages of iron meteorites were found to exceed values of $100000 \mathrm{yr}$ in about $70 \%$ of all finds. One meteorite - Tamarugal - was found to have fallen $3 \times 10^{6} \mathrm{yr}$ ago (Chang and Wänke). A new method for the determination of the cosmic-ray exposure ages has been developed based on the $\mathrm{Ar}^{36} / \mathrm{Ar}^{38}$-ratio found in the metal phase of chondrites (Nyquist et al.). Using the $\mathrm{K}^{40} / \mathrm{K}^{41}$-method, exposure ages were determined for more than 60 iron meteorites by Voshage. Medium and fine octahedrites of the Ga-Ge group III were produced in two events 600 and $700 \times 10^{6} \mathrm{yr}$ ago, while fine octahedrites of the group IVa were created $400 \times 10^{6} \mathrm{yr}$ ago. From studies of cosmic-ray produced rare gases, it was found that hexahedrites have exposure ages considerably lower than those of the other groups of iron meteorites (Wänke). Trace element studies in chondrites showed that boron belongs to the group of highly fractionated elements (Quijano-Rico and Wänke) and a solar ratio $\mathrm{B} / \mathrm{Li}=7$ was derived, instead of $\mathrm{B} / \mathrm{Li}=\mathbf{0 . 2}$ as assumed previously. In meteorites with high amounts of solar gases, indium was found to be highly enriched in the dark gas-rich portions (Rieder and Wänke), while the boron contents are nearly identical in both the light and dark portions. These findings fit well to the solar wind model of gas-rich meteorites as boron is expected to be very rare in the solar wind (Wänke). A large excess of $\mathrm{Xe}^{129}$ was detected in silicate inclusions of Campo del Cielo meteorite (Hintenberger).

The intensity of the galactic component of cosmic rays was found by Lavruchina to be two times higher at 3-5 astronomical units in comparison with those measured within the Earth's orbit, using models of the atomic reactions compared with meteorite measurements.

Extensive work on meteorites has been carried out in various laboratories in France since 1966. Ion-sputtering mass-spectrometry has been used to study the isotopic composition of lithium $\left(\mathrm{Li}^{7} / \mathrm{Li}^{6}\right)$ in several meteorites as compared to terrestrial samples. The very large variations found in the Holbrook chondrite by other investigators were due to instrumental effects (Gradsztajn et al.). Residual variations of $\pm 10 \%$ remained in some chondrites (Mezo-Madaras, Richardton) while variations in terrestrial samples (granite, hornblende) did not exceed $\pm 2 \%$ (Bernas et al.). Possible solar cosmic-ray effects induced by slow neutrons in different meteorites have been put forward by Yokoyama, indicating a trend for a cometary origin of chondrites. Galactic cosmic-ray induced nuclides and formation rates by several processes have been measured and calculated for the St-Séverin chondrite (Tobailem et al.) and the Granés chondrite (Bibron et al., Nabuchi et al.). Track method has been used to study the depth variation of track densities in meteoritic detectors from cores taken in the least ablated regions of St-Séverin (Cantelaube $e t$ al.). The implications of these results for the time-averaged flux and energy spectrum of galactic cosmic-ray iron-group nuclei during the last $12 \times 10^{6} \mathrm{yr}$ have been discussed in collaboration with the Tata Institute of Bombay (Lal et al.). Evidence has been shown for the presence of an appreciable flux of low energy protons $(10<E<300 \mathrm{MeV})$ in the least ablated regions of St-Séverin at distances of the order of 2-3 A.U., by means of correlated studies of track densities and induced activities of some cosmonuclides (Amin et al.). Observations have been reported of a low energy particle irradiation in some crystals from dark portions of gas-rich chondrites and achondrites. This low energy particle flux is thought to have an early solar origin and to have been recorded in pyroxene crystals before their accretion (Pellas et al., Poupeau et al.).

Great progress in the study of the chemical composition of meteorites is characteristic for the last several years. Neutron activation analysis was used for trace elements by many investigators. New methods for investigating the major constituents were developed by Javnel', Djakonova, 
Charitonova, Moss, Ahrens, Sprenkel-Segel, Herr and others. Wasson proposed a classification of iron meteorites into 9 groups, based on $\mathrm{Ga}$ and $\mathrm{Ge}$ content, which differ in cooling rate. In Finland, the analyzing of the major constituent elements in meteorites is going on. Wiik prepared for press a summary of this activity containing 112 complete analyses. He concludes that meteorites are not products of differentiation. The fractionation of some abundant siderophile and lithophile elements in chondrites was examined and some rules for their ratios were found by Javnel' and Ahrens.

Many papers were devoted to the composition and structure of different constituents, phases, minerals and chondrules in meteorites, which is the base for considerations about the meteorite origin. The development of sensitive methods yielded almost 20 new minerals in meteorites (Buseck, Fuchs, Olsen, Keil, Ramdohr, Faust et al.). Many measurements of organic compounds (Oro, Nooner, Hayes, Vdovykin et al.) point more to the non-biogenic origin in meteorites.

An active group is working on meteorites in Austria (Kurat). Investigations of the plessite formation in iron meteorites showed that phosphorus and carbon exert a great influence on the $\gamma \rightarrow \alpha+\gamma$ transformation (Dörfler). Also the nucleation mechanism of iron-nickel phosphides in iron meteorites has been investigated (Dörfler). Bulk and trace element analyses of several meteorites and meteoritic minerals have been performed (Schaudy, Höfler, Kiesel, Seitner, Hecht, Bauer).

The new hypersthene achondrite Peckelsheim (fall of 1953, March 18) was recovered and studied with the electron microprobe and X-ray techniques (Ramdohr, El Goresy). Detailed mineralogical studies were carried out on stony and iron meteorites by Ramdohr in Heidelberg. Zircon was observed in the chondrite Muizenberg. The composition of coexisting sphalerite, daubreelite and troilite in iron meteorites was discussed by El Goresy from Heidelberg.

An active group in Jena, German Democratic Republic (Heide, Brückner, Doenitz, Illner, Schrön) is engaged in studies of the following problems: new meteoritic stone Wolamo, stony meteorite Aukober, structure of rhabdites, magnetic behaviour of cohenite, schreibersite and/nickel-iron, the schreibersite group, meteoritical glass, motion evidence in meteorites.

Much work was done on conditions of the chondrule formation. Chondrules should have been formed as a mechanical mixture with metal and sulfide particles (Kvaša). The appearance of secondary chondrules (Frederiksson) disagrees with the theory of direct formation by condensation. On the other hand the similarity of chondrule structure and shock-melted material of some chondrites are in favour of it (Wlotzka). Another aspect of the origin of chondrules was discussed by Kurat. His petrological investigation of chondrules points to a possible magmatic origin. Crystallization of the chondrule minerals should have taken place from a strongly undercooled melt. Detailed investigations of glass-bearing chondrules showed further that chondrules from "unequilibrated" chondrites are the products of several complex and overlapping processes and that condensation and/or vaporization took place during the final stage of chondrule formation.

Data on metamorphism in chondrites point to changes of their structure and composition at $400^{\circ}-820^{\circ} \mathrm{C}$ at static pressures of about $1-2 \mathrm{kbar}$, probably during the secondary heating. The structure of iron meteorites demonstrates their pre-atmospheric dynamical deformations (Axon, Baldanza). These deformations for the Ga-Ge group III originated from a shock with a pressure exceeding $130 \mathrm{kbar}$ (Jain, Lipschutz). The dynamically deformed structures in a number of meteorites, both irons and stones, led to the recognition that differences exist between deformations due to a relatively "sudden" dynamic event and others which seem more likely due to a prolonged stress action (Baldanza and Pialli). A new concept was put forward by Suess and Wänke (Mainz) about the metamorphosis and equilibration processes in chondrites.

The thermoresistant nature of meteorite magnetization was measured by Gus'kova for different types of meteorites, by heating them to about $800^{\circ} \mathrm{C}$ in magnetic fields of 0.2 to $0.6 \mathrm{Oe}$.

Computations of meteorite orbits point out that the source of meteorites cannot be the Moon or comets, and also the asteroids of the Apollo family crossing the Mars orbit are not a very probable source (Anders, Mellick). A more probable source could be the asteroids with aphelions close to Jupiter (Wetherill), though the observational results are not completely in agreement with it (Levin, Simonenko). A majority of scientists is inclined to assume that meteorites were formed 
from asteroidal bodies with diameters of several hundred kilometers. There are some theories of lunar origin of some classes of meteorites (Urey, Wänke), which were supported by a similarity in composition of achondrites rich in $\mathrm{Ca}$ and lunar materials (Vinogradov). Levin reviewed the data on the origin of meteorites and compared them with the data on the planetary cosmogony. He continued to defend the role of diffusion in the solid state in the formation of different types of meteorites.

Experiments on meteorite ablation and fragmentation in the Earth's atmosphere were done (Bronšten, Lebedinec, Portnjagin, Fadeenko). The extent of atmospheric ablation in the St-Séverin meteorite has been measured by the track-method and corresponds to $25-30 \%$ of the preatmospheric mass (Cantelaube, Pellas et al.).

The fusion crust of meteorites and chromite variations in chondrites were studied by Ramdohr. El Goresy and Fechtig compared the fusion crust of iron meteorites and mesosiderites with cosmic spherules. The fusion crust was studied also by Judin.

About 1000 individual pieces of the Sikhote-Alin meteorite produced by atmospheric fragmentation were found by the expeditions organized during 1967 to 1969 by Krinov.

Theoretical studies of shock waves produced by meteorites during their atmospheric flight were published by Cikulin (1969). Many papers contain problems of meteorite craters, their recognition by mineralogical, structural, and other symptoms, and theoretical studies of huge meteorite impacts with the solid surface of the Earth and other planets (Symposium on Shock Metamorphism, Ed. French and Short, 1968; Stanjukovič, 1968).

\section{REFERENCES}

Anders, E., Taylor, S. R., Levinson, A. A. (eds.) 1967, Meteorites and Tektites, Geochim. Cosmochim. Acta, 31, no. 10.

Chirvinskij, P. N. 1967, Pallasites, Moscow.

Cikulin, M. A. 1969, Shock Waves Produced by Motion of Large Meteoric Bodies in the Atmosphere, Moscow.

Fesenkov, V. G., Krinov, E. L. (eds.) 1968-70, Meteoritika, nos. 28-30.

French, B. M., Short, N. M. (eds.) 1968, Shock Metamorphism of Natural Materials, Baltimore.

Hoffleit, D. (ed.) 1967-70, Meteoritics, 3-4.

Javnel', A. A. (ed.) 1968, Bibliographic Guide to the Literature on Meteoritics, nos. 14-16 (1964-1966). Javnel', A. A. (ed.) 1970, Bibliographic Guide to the Literature on Meteoritics, nos. 17-18 (1967-68).

Kielbasinski, J., Wanat, L. $\quad 1968$, Isotopic and Elemental Composition of Meteorites. A bibliography: 19471967, Warsaw.

Krinov, E. L. (ed.) 1967-1969, The Meteoritical Bulletin, nos. 39-48.

Millman, P. M. (ed.) 1969, Meteorite Research, D. Reidel, Dordrecht, Holland.

Stanjukovič, K. P. (ed.) 1968, Explosive Craters on the Earth and Planets, Moscow.

UNESCO 1968, Directory of Meteorite Collections and Meteorite Research, Paris.

Vdovykin, G. P. 1967, Carbon Matter of Meteorites, Moscow.

Wood, J. A. 1968, Meteorites and the Origin of Planets, New York.

A. A. JAVNEL'

Chairman of the Committee

\section{METEORITE RESEARCH IN THE U.S.A. AND CANADA}

\section{Chondrites}

There have been considerable improvements in the classification of chondrites. Van Schmus and Wood have subdivided each of the major classes into 4 petrological groups, differing in degree of recrystallization. This classification seems to be of rather profound significance: though based entirely on textural criteria, it correlates remarkably well with compositional features, such as content of primordial gases, In, and $\mathrm{C}$. Several detailed studies of individual chondrite classes have appeared: enstatite, amphoterite, type III carbonaceous, and unequilibrated ordinary. 
Much effort has been spent on major and minor element abundances. Larimer and Anders have tried to explain the observed trends by fractionation processes in the solar nebula. Wood and Dodd, on the other hand, ascribe most of them to metamorphism in the meteorite parent bodies. The reality of metamorphism has been questioned in a spirited debate, but recent work by Hohenberg and Reynolds ( $\mathrm{Xe}^{129}$ retention in chondrites) and Dundon and Walter $\left(\mathrm{Fe}^{2+}-\mathrm{Mg}^{2+}\right.$ disorder in pyroxenes) and others strengthened the case for it. Arguments on the origin of chondrites continue. Blander et al. agree with Wood and Larimer and Anders that the chondrites are basically a direct condensate from the solar nebula, but show that supercooling of the gas may have had an important influence on the nature of the condensate. Wood concludes from a study of carbonaceous chondrites that their chondrules formed in a region of the nebula where dust had been concentrated 5000 -fold relative to the gas. Larimer has attempted to reconstruct the formation conditions of enstatite chondrites from petrological considerations. A study of metal particles in chondrites shows that they cooled through $500^{\circ} \mathrm{C}$ at a rate of 0.2 to $10 \mathrm{deg} / 10^{6} \mathrm{yr}$ (Wood). This suggests that the parent bodies were of asteroidal size. Arguments for a lunar origin were presented by Urey.

\section{Irons}

Here, too, a new and superior classification system has been developed by Goldstein. It is based on $\mathrm{Ga}, \mathrm{Ge}$, Ir and $\mathrm{Ni}$ contents (mainly due to Wasson), and on cooling rates (mainly due to Goldstein and Short). Most iron meteorites fall into one of 14 groups. The range of cooling rates is 0.5 to $500 \mathrm{deg} / 10^{6} \mathrm{yr}$, which corresponds to parent bodies of asteroidal size. Lipschutz et al. noted that one of these groups (III) consistently shows rather severe shock effects, which implies high ejection velocities. They suggest that these meteorites originated from an asteroid whose orbit did not cross that of Mars. In that case only fragments ejected at high velocities had a chance of eventually being deffected into an Earth-crossing orbit. The radiation age of these meteorites is about $600 \times 10^{6} \mathrm{yr}$, which may indicate the date of the collision.

Two minerals often thought to imply a high-pressure origin of meteorites have been reinterpreted. Diamond from Canyon Diablo and several other shocked meteorites turned out to contain a new, hexagonal modification (lonsdaleite), stable only above $130 \mathrm{kbar}$. Hydrostatic pressures of this order can be attained only in bodies well above lunar size, but such bodies would resist disruption and hence cannot serve as the source of meteorites. Graphite particles of cubic habit (= cliftonite), sometimes regarded to be pseudomorphs after diamond, were synthesized by Brett and Higgins at low pressures, using nickel-iron alloys saturated with carbon.

\section{Stony irons}

Pallasites and mesosiderites were studied by Buseck et al. and Powell. Their cooling rates are lower than those of irons, suggesting an origin in larger bodies.

\section{Achondrites}

Duke and Silver reported a comprehensive petrographic study of 21 eucrites and howardites, and 3 mesosiderites. Two other studies of fairly broad scope were published by Mason and Schnetzler and Philpotts.

\section{Meteoritic minerals}

A number of new phosphate minerals were discovered by Fuchs and Olsen. Other new minerals (or first meteoritic occurrences) were: potassium feldspar, amphibole, yagiite, niningerite, garnet and brezinaite. Among the well-established minerals, the following were the subject of intensive study: feldspar, chromite, cohenite, pyroxenes, schreibersite and ilmenite. A review of meteoritic minerals was written by Mason. 


\section{Ages}

This has continued to be the most active field of meteorite research. Much of the effort was devoted to extinct radioactivity, notably $16 \times 10^{6} \mathrm{yr} \mathrm{I}^{129}$ and $82 \times 10^{6} \mathrm{yr} \mathrm{Pu}^{244}$. An early report by Hohenberg et al. suggested that all chondrites began to retain $\mathrm{Xe}^{129}$ in high-temperature sites within $\pm 2 \times 10^{6} \mathrm{yr}$. But more recent study by Podosek shows measurable time differences from one chondrite to another. The total range for 10 chondrites and 2 aubrites is $14 \times 10^{6} \mathrm{yr}$. Retention of $\mathrm{Xe}^{129}$ in low-temperature sites took considerably longer, about $100 \times 10^{6} \mathrm{yr}$. Thus the cooling curve of meteorites seems to have been fairly steep initially (greater than $100 \mathrm{deg} / 10^{6} \mathrm{yr}$ ?), flattening out afterwards to about $1-10 \mathrm{deg} / 10^{6} \mathrm{yr}$. It is remarkable how well the cooling rates determined by different techniques agree with each other. Fleischer et al. have derived a cooling rate of $\left(1.1_{-0.5}^{+0.6}\right) \mathrm{deg} / 10^{6} \mathrm{yr}$ for the iron meteorite Toluca, using fission tracks of $\mathrm{Pu}^{244}$. This result agrees quite closely with the metallurgically determined value, which in turn agrees with that based on $\mathrm{Xe}^{129}$. Other studies of fission- or cosmic-ray-induced tracks in meteorites have given much new information. The space erosion rate of the Patwar mesosiderite was found to be less than $0.1 \mathrm{~mm} / 10^{6} \mathrm{yr}$, far below previous estimates. The abundance distribution of heavy nuclei in cosmic radiation has not changed much in the last $10^{7} \mathrm{yr}$.

Careful isotopic analyses of xenon have shown that calcium-rich achondrites contain one kind of fission-produced component, probably from $\mathrm{Pu}^{244}$, while chondrites contain another. It has been suggested that the progenitor of the latter type of xenon might be an extinct super-heavy element of $Z=112-119$.

A controversy has arisen over the usefulness of $\mathrm{Pu}^{244}$ for dating purposes. Kuroda et al. maintain that meaningful and concordant $\mathrm{Pu}^{244}-\mathrm{Xe}^{136}$ and $\mathrm{I}^{129}-\mathrm{Xe}^{129}$ ages can be obtained by using the initial abundances of the two extinct nuclides predicted by a "constant-rate, continuous nucleosynthesis" model. But Reynolds has pointed out various ambiguities in the interpretation of the data, and Fisher has shown that some of the uranium contents assumed by Kuroda were in error. Moreover, the nucleosynthesis model itself is open to question. Dicke and Hohenberg have re-evaluated the available evidence, and conclude that the continuous nucleosynthesis model is an oversimplification. Numerous other studies on meteoritic $\mathrm{Xe}$ and $\mathrm{Kr}$ have appeared. Marti has shown that radiation ages of stony meteorites can be determined from $\mathrm{Kr}^{81} / \mathrm{Kr}^{83}$ ratios.

The $\mathrm{Rb}^{87}-\mathrm{Sr}^{87}$ dating method has yielded several interesting results. By an extraordinary improvement in technique, Papanastassiou and Wasserburg were able to show that 7 eucrites had formed within $4 \times 10^{6} \mathrm{yr}$ of each other, $4.39 \pm 0.26 \times 10^{9} \mathrm{yr}$ ago. In view of the long half-life of $\mathrm{Rb}^{87}\left(50 \times 10^{9} \mathrm{yr}\right)$, the resolution of such fine time differences must be regarded as an extraordinary achievement. The brecciated octahedrite Kodaikanal was found to have $\mathbf{R b}-\mathrm{Sr}$ age of only $3.8 \pm 0.1 \times 10^{9} \mathrm{yr}$. This is the first well-documented case of a meteorite originating after the era of meteorite formation $4.5 \times 10^{9} \mathrm{yr}$ ago.

Several more or less complete surveys of individual meteorite classes were published. Most of the L-chondrites seem to have been involved in a collision $520 \times 10^{6} \mathrm{yr}$ ago, and must therefore come from a single body.

\section{Primordial gases}

This field is in a state of flux. For some years, the prevailing notion was that primordial gas consisted of two components, differing in elemental composition: an unfractionated ("solar") and a fractionated ("planetary") component. Isotopic differences between the two components were first noted for $\mathrm{Ne}$ then for $\mathrm{He}$ and $\mathrm{Xe}$. Recent studies suggest, however, that $\mathrm{Ne}$ is still more complex: as many as 5 different subcomponents may be present (Black, Pepin). At least one of the unfractionated components may be derived from the solar wind, but the trapping mechanism is still under dispute.

\section{Radioactivity}

Fireman has continued his methodical study of $\mathrm{H}^{3}, \mathrm{Na}^{22}, \mathrm{Al}^{26}, \mathrm{Ar}^{37}$, and $\mathrm{Ar}^{39}$ in freshly fallen 
meteorites. He concludes that the 11-yr cosmic-ray variation is smaller at the average solar distance of most metteoroids than at 1 A.U., and that the heliocentric radial gradient of the high-energy component is $20 \pm 8 \% /$ A.U. of solar maximum and minimum. Kohman and Bender have done extensive calculations on the cosmic-ray production rate of various nuclides as a function of meteoroid size and depth. A review of similar scope was written by Kirsten and Schaeffer. Several experimental studies on $\mathbf{A l}^{26}$ and other radionuclides have been reported.

\section{Orbits}

(Prairie Network: see the Commission Report). Wetherill redetermined the collision frequency in the asteroidal belt and used Arnold's Monte Carlo model to test various possible parent objects for their ability to produce meteorites with the proper characteristics: radiation ages, morningafternoon fall frequency, and elongation of radiant. Anders and Mellick used a similar, though less ambitious approach to search for a parent object that would produce Príbram-like orbits with appreciable frequency. Fisher questioned the predominance of afternoon falls, long accepted as a well-observed characteristic.

\section{Organic compounds}

Oró et al. have made a comprehensive survey of heavy hydrocarbons in most of the known carbonaceous chondrites. A few meteorites were studied in greater detail by Hayes and Biemann and Studier $e t$ al. The latter authors showed that most compounds reliably identified in meteorites could be synthesized from $\mathrm{CO}$ and $\mathrm{H}_{2}$ in the presence of iron meteoritic powder, which acts as a catalyst. Similar reactions may have taken place in the solar nebula. An extensive review of this field has been given by Hayes. Shorter reviews were written by McCarthy and Calvin and Nagy.

\section{Meteorite craters}

Several detailed descriptions of Canadian craters have appeared. Shock features due to meteorite impact have now been identified in 17 Canadian craters (Beals, Halliday). Theages of the Manicouagan and Clearwater craters were determined as $208 \pm 25 \times 10^{6}$ yr and $100-300 \times 10^{6}$ yr by fission track dating (Fleischer et al.). The latter figure is consistent with a more-accurately determined K-Ar age of $300 \times 10^{6} \mathrm{yr}$. French has presented evidence for an impact origin of the Sudbury structure. A brief review of terrestrial craters was given by Beals and Halliday. 